\title{
ISSN 1414-6509 \\ A EXPANSÃO DA REDE FEDERAL DE EDUCAÇÃO PROFISSIONAL, TÉCNICA E TECNOLÓGICA NO PERÍODO 2003-2014: UMA ANÁLISE A PARTIR DA ABORDAGEM DAS CAPACITAÇÕES ${ }^{1}$
}

\author{
Marcelo Mallet Siqueira Campos \\ Professor do IFRS. \\ Endereço: Rua Santos Dumont, 2127. Bairro Albatroz. Osório - RS. \\ CEP: 95.520-000 E-mail: marcelosiqueiracampos@ gmail.com
}

\section{RESUMO}

Este artigo analisa a expansão verificada na rede federal de ensino, com ênfase na rede federal de educação profissional, científica e tecnológica. A política econômica é compreendida aqui de maneira ampla, incorporando a política educacional. Para isto, é exposto um breve histórico da educação profissional no mundo, em consonância com as necessidades surgidas a partir da Revolução Industrial. A educação aparece atrelada ao desenvolvimento econômico, podendo, por vezes, negligenciar a busca pelo desenvolvimento intelectual como um fim em si mesmo. A partir daí, é realizada uma breve explanação a respeito da educação no Brasil. As contribuições da abordagem das capacitações, desenvolvida a partir das obras de Amartya Sen, são explicitadas, com foco na educação como uma importante liberdade substantiva para que as pessoas possam viver do modo que acham racionalmente melhor. Procura-se analisar a expansão da educação profissional no Brasil à luz da abordagem das capacitações, questionando se essa atende aos princípios do desenvolvimento humano.

PALAVRAS CHAVE: educação profissional, abordagem das capacitações, desenvolvimento humano.

\begin{abstract}
This article analyzes the expansion recorded of federal network of education, with emphasis on the federal network of professional, scientific and technological education. Economic policy is understood here in a broad sense incorporating the educational policy. For this, is exposed a brief history of vocational education in the world, in accordance with the needs that emerged from Industrial Revolution. Thereafter, is made a brief explanation about education in Brazil. The contributions of the capabilities approach, developed from the work of Amartya Sen are exposed, with focus on education and the expansion of capabilities. Finally, the expansion of vocational education in Brazil is analyzed considering the capabilities approach.
\end{abstract}

KEY WORDS: professional education, capabilities approach, human development.

\footnotetext{
${ }^{1}$ Trabalho premiado no IV Seminário de Jovens Pesquisadores em Economia e Desenvolvimento.
} 


\section{INTRODUÇÃO}

Os economistas, reconhecidos pela persistência de opiniões divergentes, costumam convergir em poucos assuntos, um deles é a relevância da educação. Independente de orientação ideológica, grande parte dos economistas costuma concordar em relação à importância da educação na promoção do desenvolvimento econômico. Seja pelo capital humano ser a fonte de diferença de produtividade entre diferentes países (na visão neoclássica) seja por ela fornecer condições para que a população rompa com as condições de privações graves (na visão seniana).

Como a educação possui uma relação importante com o desenvolvimento econômico, este artigo se propõe a fazer uma análise da política educacional, a partir de uma mudança institucional, a criação dos Institutos Federais de Educação Ciência e Tecnologia, parte importante da política de expansão da educação profissional, técnica e tecnológica. A ação estatal na promoção do desenvolvimento econômico será compreendida em sentido mais amplo, como fez Fonseca (2003), que analisou a intencionalidade da política industrializante de Vargas, indo além dos estudos focados nas políticas monetária e cambial, ao focar nas instituições. Entre as medidas adotadas por Vargas em prol do desenvolvimento (então visto como sinônimo de industrialização) destacam-se a criação de diversos órgãos, conselhos e institutos, sem falar da reforma educacional, iniciada em 1931. Como parte desta reforma, estava a criação de cursos técnicos e profissionalizantes, voltados a áreas como engenharia, agronomia e contabilidade. A qualificação da educação visava aumento da riqueza, via elevação da produtividade e melhoria das condições do trabalhador (FONSECA, 2003, p. 145).

O objetivo deste artigo é analisar a expansão verificada na rede federal de ensino, com ênfase na rede federal de educação profissional e tecnológica, sob a ótica da abordagem das capacitações, de Amartya Sen. A hipótese deste trabalho é que o investimento em educação é uma das vias de expansão das capacitações nos governos Lula (2003-2010) e Dilma (2011-2014).

Neste sentido, este artigo busca analisar a consolidação de Rede Federal de Educação Profissional e Tecnológica, entre 2003 e 2014, com a criação dos Institutos Federais de Educação, Ciência e Tecnologia em 2008 e sua posterior expansão. A política do governo federal em relação à educação será considerando como um dos pilares da política de promoção do desenvolvimento econômico em sentido amplo, não restrito à política macroeconômica. A expansão do ensino, somada às políticas voltadas para uma distribuição de renda mais equitativa (programas de transferência de renda, elevação real do salário mínimo, e redução do desemprego) são as bases de uma política voltada para a expansão das capacitações, em consonância com a teoria desenvolvida por Amartya Sen.

Para isto, será inicialmente contextualizado o papel da educação profissional, para seguir com a descrição da trajetória desta modalidade de ensino no Brasil com suas mudanças recentes. A seguir, será apresentada a abordagem das capacitações, que fornece a base para a compreensão deste processo. 


\section{HISTÓRICO DA EDUCAÇÃO PROFISSIONAL}

Esta seção se propõe a expor uma breve descrição da educação profissional no mundo, em consonância com as necessidades surgidas a partir da Revolução Industrial, para, então, realizar uma breve explanação a respeito da educação no Brasil.

A Inglaterra fez a Revolução Industrial, baseada primeiramente em inovações simples, ocorridas no nível das fábricas, num aprendizado classificado como learning by doing. Os países da Europa continental, procurando alcançar os ganhos de produtividade obtidos pelos britânicos, sistematizam a educação profissional. É o caso da fundação da École Polytechnique ${ }^{2}$ na França em 1794, pelo governo revolucionário ${ }^{3}$, nomeando um corpo docente de cientistas e matemáticos ${ }^{4}$. Sua criação foi seguida por écoles d'arts e métiers, frequentemente fundadas por empregadores, para treinamento em determinados ramos: química em Lyon, relojoaria em Besançon, têxteis em Mulhouse (LANDES, 1999, p. 282-283).

A iniciativa francesa foi copiada pelos países ao leste, com o surgimento de politécnicas em Praga, Viena, Zurique, Estocolmo, Copenhague, Moscou e São Petersburgo. A Alemanha também desenvolveu seu sistema de ensino, em moldes próprios, e que veio a se tornar referência no resto do mundo. Ele consistia em uma rede de escolas de negócios (Gewerbeschulen) e de escolas técnicas (technische Hochschulen). A primeira, delas fundada em Karlsruhe em 1825, formou químicos e engenheiros em nível universitário. O mais importante foi que os alemães deram propulsão a instrução científica e a pesquisa nas universidades, criando laboratórios de ensino.

Se a Revolução Industrial, em sua primeira onda, foi resultado da estratégia britânica do learning by doing, que deu enormes resultados, principalmente na indústria têxtil, nas fases seguintes esta estratégia não foi mais tão decisiva. Em uma perspectiva de longo prazo, as escolas de ciência e tecnologia foram mais importantes (LANDES, 1999, p. 282). A estratégia continental de escolarização deu resultados, visto que a química e a elétrica, a partir de então diretamente ligadas à atividade industrial, dependem de educação formal. O catching up dos países continentais tornou-se um salto para frente, com estes países assumindo a vanguarda tecnológica, com a criação de novas tecnologias e sua melhoria. O casamento entre ciência e tecnologia inaugurou o fenômeno conhecido como crescimento econômico moderno.

2 Landes (1999, p. 282) destaca o caráter competitivo desta instituição, com admissão aberta por meio de exames, atraindo os melhores e mais brilhantes da França, em contraposição com o sistema vigente no Antigo Regime.

$3 \mathrm{O}$ progresso foi imenso, embora a quantidade de pessoas instruídas continuasse pequeno dentre a população. Hobsbawm (2006, p.193) chama atenção para a pequena quantidade de alunos: o ingresso na Polytechnique era de cerca de cem alunos por ano; e mesmo que o número de alunos nos liceus estatais tenha dobrado nas primeiras décadas do século XIX, em 1842, eram menos de 19 mil alunos matriculados. 4 A realização crucial da Revolução Industrial e da Revolução Francesa foi, para Hobsbawm (2006, p.265267), a abertura das carreiras para o talento e o esforço. A educação, antes restrita, passou a ser uma estrada aberta a todos, propiciando três possibilidades: o funcionalismo público, a política e as profissões liberais. 
Enquanto este movimento ocorria na Europa continental, o Brasil recém constituía-se. A educação pública só surge, no Brasil, durante o século XIX. O intuito era preparar as elites, que durante todo o período colonial estudavam na Europa, principalmente na Universidade de Coimbra, em Portugal, assim como na França. A estratégia deliberada da coroa portuguesa foi não criar universidades em território brasileiro. Esta estratégia estava alinhada com o objetivo de manter a coesão do estamento burocrático dominante (CARVALHO, 2007).

Ao contrário da América Portuguesa, os espanhóis, principalmente através dos jesuítas, difundiram o ensino universitário ao longo de suas colônias. Se a primeira universidade brasileira data do século XX, em outros países do continente a fundação das primeiras universidades remete ao século XVI. Onde havia universidade, ocorreu formação de elites locais, com pensamento relativamente coeso entre si, mas independente das demais. Já no Brasil, mesmo geograficamente distantes, os membros do estamento burocrático possuíam a mesma formação, favorecendo a homogeneização do pensamento.

Foi apenas ao longo do século XX, que ocorreu a expansão e a democratização do ensino público no Brasil, principalmente após as décadas de 1930, 1940 (nos governos de Getúlio Vargas) e 1950 (no Governo Juscelino Kubitschek). Até a década de 1930 o ensino era centrado nas áreas humanas: latim, retórica, francês, filosofia, história, geografia e literatura.

O ensino profissionalizante surge ainda durante a República Velha, no final da década de 1900, por iniciativa do então presidente Nilo Peçanha, a partir de proposta anterior do Marechal Deodoro da Fonseca, quando foi instalada em cada capital brasileira uma Escola de Aprendizes Artífices, por meio do Decreto $\mathrm{n}^{\circ} 7.566$, de 23 de setembro de 1909 (KUNZE, 2009). Neste contexto, cabia às escolas da rede federal:

A incumbência de difundir, em especial, a essa clientela, os valores e preceitos do novo regime governamental, os hábitos do trabalho e da obediência às regras e uma formação profissional, uma profissão, um ofício, que a transformasse em operários frutíferos à nação, trabalhadores ordeiros e qualificados para atuarem nas futuras indústrias brasileiras. (KUNZE, 2009, p. 22).

A educação voltada para o trabalho visava, então, afastar os pobres e desvalidos de fortuna da ociosidade do vício e do crime. Esta visão foi dominante até o estabelecimento do projeto de industrialização a partir de 1930.

Em 1931, Francisco Campos então ministro da educação inicia uma reforma da educação, considerada exclusivamente teórica e elitista. É proposta a criação de "cursos técnicos e profissionalizantes, centrados em áreas voltadas diretamente à produção como engenharia, agronomia e contabilidade" (FONSECA, 2003, p. 145). Vargas e seu ministro viam que a criação de riqueza dependia das qualificações e boas condições físicas dos trabalhadores, "capital humano aplicável ao aproveitamento integral das nossas condições excepcionais de riqueza” (VARGAS, 1938, v. 3: p. 246, apud FONSECA, 2003, p. 145). 
O pensamento de Vargas, o afastava da elite agrária tradicional, uma vez que este estava buscando a modernização do país a partir da industrialização (WINCKLER; SANTAGADA, 2012, p. 98-99).

Durante o Estado Novo, Getúlio Vargas incentiva a educação para o trabalho por meio da criação do sistema S: SENAI em 1943 e SESI em 1944 (FONSECA, 2003, p. 144), visando fornecer trabalhadores capacitados para o processo de industrialização da economia brasileira que então se iniciava, e propor soluções técnicas para os problemas da indústria nacional, bem como da mineração e da agricultura, compreendidas como fundamentais para o desenvolvimento do país.

Durante o governo Juscelino Kubitschek a educação profissionalizante passou por um período de expansão, com as instituições federais passando à condição de autarquia, adquirindo autonomia didática e de gestão. Nesse período (1956-1961), foram criados diversos centros para educação agrícola e industrial, em consonância com o Plano de Metas, que visava aprofundar a industrialização em curso na economia brasileira. A tendência tecnicista já existente se acentua (WINCKLER; SANTAGADA, 2012, p. 9899).

A industrialização do Brasil ocorreu num modelo de parâmetros fordistas e tayloristas, de produção em massa. A educação profissional se adaptou a este modelo, separando as atividades intelectuais-dirigentes e operacionais, fragmentando a formação pedagógica, levando a separação entre o ensino propedêutico e profissional (WINCKLER; SANTAGADA, 2012, p. 99). É necessário ressaltar que o ensino, tanto público quanto privado, estava disponível apenas a uma parcela da classe trabalhadora. Em 1960, entre a população adulta (com mais de 15 anos) no Brasil, menos de 2\% possuía ensino superior, $14,3 \%$ ensino médio e apenas $36,4 \%$ ensino fundamental. Até o final do século XX houve uma forte expansão no ensino fundamental. No ano $2000 \mathrm{o}$ percentual da população adulta com ensino fundamental aumentou para 62,2\%, no entanto, o ensino médio pouco avançou, para $14,4 \%{ }^{5}$ (pois havia em meados da década de 1970 recuado para 7,7\%), e o ensino superior avançou para 7,5\% (FERREIRA, VELOSO, 2005, p. 383), bastante, se comparado com o ponto de partida, mas insuficiente para aproximar o Brasil dos patamares observados nas economias desenvolvidas.

O Gasto Público em educação avançou de 1,4\% do PIB em 1950 para 4\% em 2000. Não obstante, no Gráfico 1 distinguem-se claramente dois períodos de aumento do gasto, no período democrático antes do golpe de 1964 e após a redemocratização ${ }^{6}$.

5 Frigotto (2007) destaca que vários entre os poucos concluintes do ensino médio nos anos 1990 preferiam migrar para outros países, face os baixos salários recebidos no Brasil. Cabe ressaltar, que em decorrência da crise nos países desenvolvidos e do crescimento econômico do Brasil nos anos 2000, este fluxo migratório se reverteu.

6 Herrlein Júnior (2011) sugere que já estariam presentes na Constituição de 1988 as origens de um Estado democrático para o desenvolvimento. 


\section{Gráfico 1: Gasto Público com educação (\% do PIB), 1950-2000}

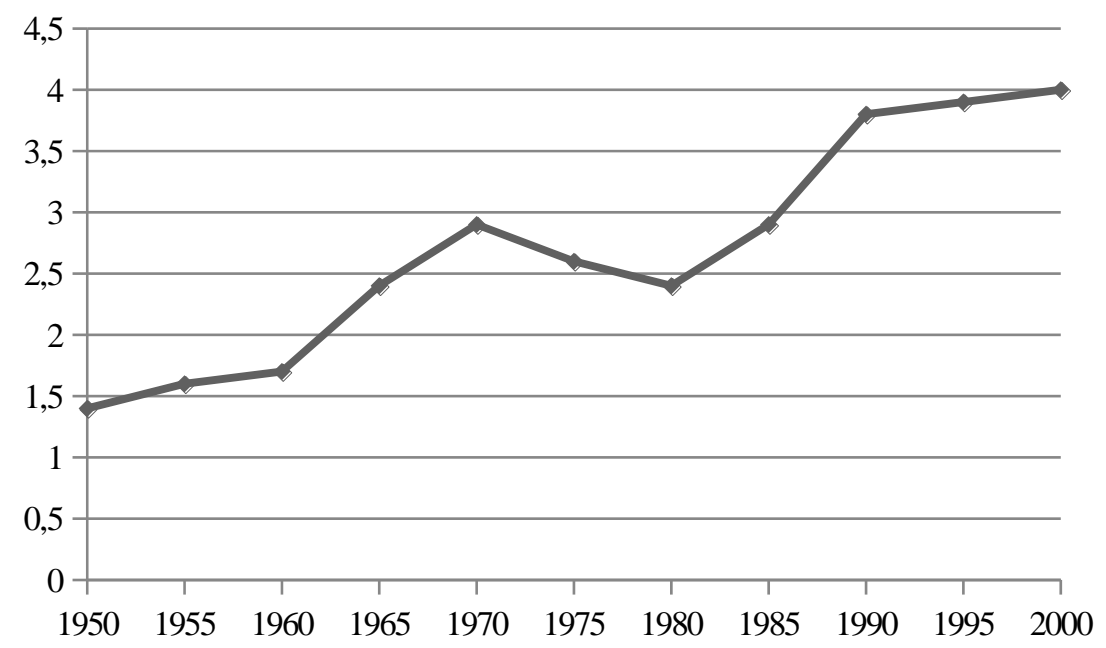

Fonte: Barbosa Filho e Pessoa (2013, p. 214).

Quanto à educação profissional, o diagnóstico vigente no governo Fernando Henrique Cardoso era de que "a rede federal de ensino técnico era custosa em comparação à do ensino médio regular" (WINCKLER; SANTAGADA, 2012, p 101) e que esta não atendia à classe trabalhadora.

Desta maneira, ao longo das décadas, a educação profissional foi sendo deixada duplamente de lado, cabendo, cada vez mais, à iniciativa privada a oferta de cursos, sendo que o foco da expansão do setor privado se deu no ensino superior. A expansão do ensino privado se iniciou na ditadura militar, a partir da reforma universitária de 1968, ganhando novo impulso com a Lei de Diretrizes e Bases da Educação Nacional (LDB) no governo Fernando Henrique Cardoso. Entre 1997 e 2002 o número de instituições privadas de ensino superior passou de 689 para $1442^{7}$. Este modelo é apontado como um limitador das possibilidades de estudantes de baixa renda (CORBUCCI, 2014, p. 8-9 e FRIGOTTO, p. 246). A filósofa Martha Nussbaum, ligada à abordagem das capacitações, critica o modelo de educação voltado ao lucro, ressaltando que um modelo de educação voltado para as elites ricas não pode ser considerado bom (NUSSBAUM, 2010).

A despeito do avanço do ensino fundamental, e da expansão do ensino superior, o Brasil iniciou o século XXI com a permanência de problemas, que mesmo entre países da América Latina, já haviam sido superados no início do século XX, como a erradicação do analfabetismo e a universalização do ensino fundamental (FRIGOTTO, 2011, p. 243). Entre 2001 e 2011, a taxa de alfabetização das pessoas com 15 anos ou mais se elevou de $87,6 \%$ para $91,4 \%$. De maneira semelhante, no início do século, a média de escolaridade

7 Kliksberg chamou atenção para a maior importância do capital humano no crescimento econômico, salientando que "no final do século, o investimento em educação transformou-se numa das áreas de maior rentabilidade. Isso tem a ver com as mudanças radicais que estão ocorrendo nas estruturas de produção" (1998, p.24). 
da população com mais de 25 anos era de 6,0 anos de estudo, passou em 2003 para 6,3, chegando a 7,3 anos de estudo em $2011^{8}$ (IBGE, 2011, p. 257-277 e IBGE, 2012, p. 128133).

A desigualdade entre os quintis da população também se reduziu. A escolaridade do primeiro quintil da população adulta aumentou, entre 2002 e 2011, de 3,4 para 5,0 anos de estudo, enquanto que no quinto quintil aumentou de 10,4 para 11,3 anos (CEPAL, 2014, p. 83). Mesmo com esta melhora, a comparação internacional, mostra o Brasil abaixo dos demais países da América Latina e Caribe, quanto à alfabetização, ao acesso ao ensino secundário, e à média de anos de escolaridade, como ilustra a Tabela 1.

Tabela 1: Alfabetização e acesso ao ensino secundário (países selecionados)

\begin{tabular}{l|c|c|c} 
& $\begin{array}{c}\text { Taxa de alfabetização de } \\
\text { adultos (15 anos ou mais) }\end{array}$ & $\begin{array}{c}\text { População com pelo menos } \\
\text { o ensino secundário (25 anos } \\
\text { ou mais) }\end{array}$ & $\begin{array}{c}\text { Média de anos } \\
\text { de escolaridade }\end{array}$ \\
\hline Cuba & 99,8 & 77,1 & 10,2 \\
Chile & 98,6 & 74,0 & 9,7 \\
Uruguai & 98,1 & 49,8 & 8,4 \\
Argentina & 97,8 & 56,0 & 9,3 \\
Venezuela & 95,5 & 52,4 & 6,2 \\
Paraguai & 93,9 & 36,9 & 7,8 \\
Colômbia & 93,4 & 43,1 & 7,4 \\
México & 93,1 & 53,9 & 8,7 \\
Equador & 91,9 & 36,6 & 7,6 \\
América Latina e & $\mathbf{9 1 , 3}$ & $\mathbf{5 0 , 4}$ & $\mathbf{7 , 9}$ \\
Caribe & 91,2 & 44,5 & 9,2 \\
Bolívia & $\mathbf{9 0 , 3}$ & $\mathbf{4 9 , 5}$ & $\mathbf{7 , 2}$ \\
Brasil & 89,6 & 52,9 & 9,6 \\
Peru & 48,7 & 29,1 & 4,9 \\
Haiti & & & \\
\hline
\end{tabular}

Fonte: PNUD (2010); PNUD (2013).

Esta dualidade, de o Brasil iniciar o século XXI tendo que lidar, simultaneamente, com problemas dos séculos XIX e XXI é, justamente, uma das características da condição de subdesenvolvimento. Moderno e arcaico coexistem lado a lado ${ }^{9}$.

8 A disparidade entre regiões também chama atenção, bem como entre cor ou raça e entre rural e urbano (IBGE, 2011 e IBGE, 2012), ainda que os investimentos da última década estejam reduzindo este hiato.

9 Frigotto (2007), resgatando as contribuições de Florestan Fernandes e Francisco de Oliveira, chama atenção para a relação dialética entre o atrasado e o desenvolvido na especificidade da formação social capitalista no Brasil. 


\section{MUDANÇA POLÍTICA E A INSERÇÃO DOS INSTITUTOS FEDERAIS}

Ao longo das décadas de 1980 e, principalmente, 1990, houve uma redução da importância estatal, com o Estado perdendo o protagonismo em diversas áreas. Este movimento teve reflexos na educação, conforme exposto na seção anterior, com uma expansão do ensino privado. A despeito das melhorias alcançadas no ensino fundamental, em relação ao ensino profissional e superior, o modelo adotado era excludente. Peter Evans (1993 e 2003) e Bernardo Kliksberg (1998) são exemplos de analistas que mostram a crítica da visão dominante, focada nas falhas da ação estatal e da repercussão negativa deste cenário para o desenvolvimento humano.

Na primeira década do século XXI o Brasil, assim como outros países latinoamericanos, passou por mudanças na orientação política. O papel do Estado no desenvolvimento econômico foi repensado. A ótica do desenvolvimento humano, que será apresentada na próxima seção, passou a guiar a ação estatal.

O Estado muda, refletindo as transformações na sociedade brasileira. É importante salientar a importância da democracia, como ressaltam Peter Evans (2003) e Amartya Sen (2000). A mudança na orientação da política parte das eleições presidenciais. A coalizão de centro-esquerda, liderada por Lula, chegou ao poder, com uma base de sustentação diversa (incluindo políticos de ideias antipopulares), mas que permite a mudança da sociedade dentro das regras vigentes que: "vêm permitindo a mudança da sociedade, das condições de vida do povo e do caráter social do Estado, através dos mecanismos de democracia das massas" (HERRLEIN JÚNIOR, 2011, p. 41). Frigotto (2011) também aponta que com a eleição de Lula, as propostas para a educação passaram a vir da própria sociedade, e não elaboradas do alto por intelectuais, como havia sido na gestão Fernando Henrique.

Houve a presença de uma conjuntura econômica favorável, aliada a um "projeto político voltado ao desenvolvimento do mercado interno, com políticas de redistribuição de renda e maior presença do Estado" (WINCKLER; SANTAGADA, 2012, p. 107). Ocorreu então, uma situação inédita de crescimento econômico com melhoria na distribuição de renda, marcada por uma paulatina redução do desemprego, simultânea ao aumento real do salário mínimo ${ }^{10}$.

Foi neste contexto que a situação da educação profissional se alterou, passando a receber um papel de destaque e investimentos do setor público, por parte do Governo Federal. Nesta retomada de investimentos, os Institutos Federais adquiriram a atual forma, constituídos em 29 de dezembro de 2008, por meio da lei no 11.892. Esta lei

10 O salário mínimo, que teve um ganho real de $22 \%$ no governo Fernando Henrique Cardoso (19952002), teve crescimento real de 58\% durante o governo Lula (2003-2010) (HERRLEIN JÚNIOR, 2011, p.19), este movimento foi mantido no primeiro mandato de Dilma (2011-2014) com aumento real de $12 \%$. 
institui a Rede Federal de Educação Profissional Científica e Tecnológica ${ }^{11}$, que tem como base o princípio do ensino público, gratuito e de qualidade, que permeia todas as instituições federais que atuam com ensino superior. Frigotto (2007, p. 1141-1142) apontou que a demora do governo Lula em iniciar o processo de expansão da educação profissional ocorreu pela necessidade de alterações legais. Levaram-se quase dois anos para revogação do Decreto n. 2.208 de 1997, que instituía a política do governo anterior para a educação profissional, que impedia a expansão da educação profissional pela esfera federal.

Ao longo de quase um século, desde o surgimento das escolas de Aprendizes Artífices até 2002, foram criadas no Brasil 140 escolas técnicas na rede federal. Com a unificação da Rede Federal de Educação Profissional, Científica e Tecnológica e a criação dos Institutos Federais de Educação, Ciência e Tecnologia em 2008, este número aumentou para 366 em 2010 e chagando, em 2014, na existência de 562 escolas.

\section{Gráfico 2: Expansão da Rede Federal de Educação Profissional, Científica e Tecnológica (em número de escolas), 2002-2014}

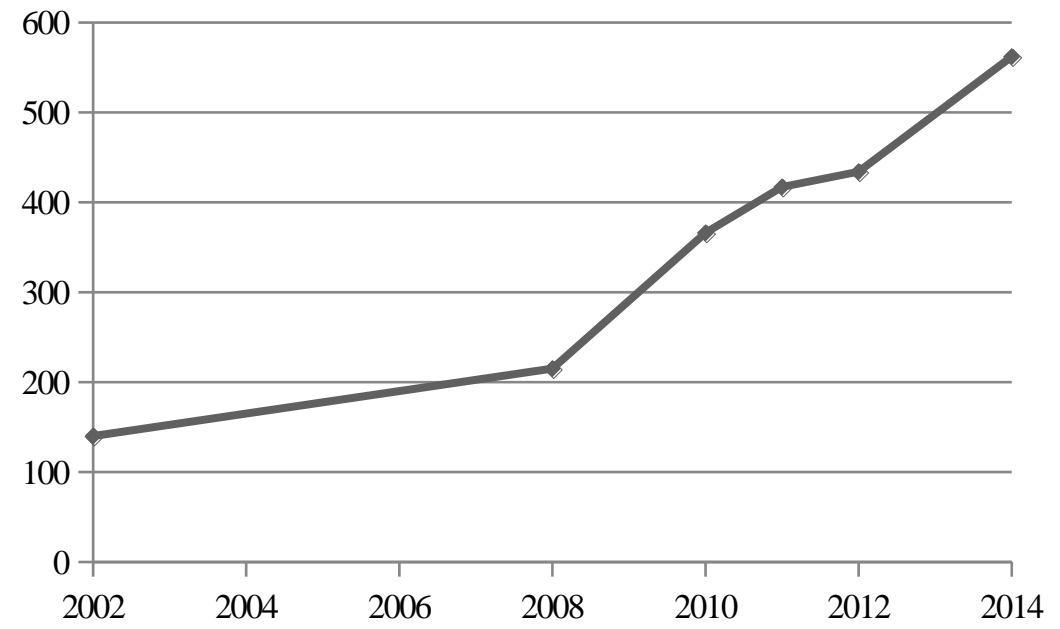

Fonte: MEC (2014).

De acordo com a lei que cria os Institutos Federais, estes têm como objetivos um claro vinculo entre a teoria e a prática, voltado para a formação da mão de obra, mesmo na formação de licenciaturas ${ }^{12}$. Estes objetivos são múltiplos e visam superar muitos dos entraves ao desenvolvimento do Brasil, que têm origem em deficiências no ensino, ou

11 Composta, além dos Institutos Federais, pela Universidade Tecnológica Federal do Paraná, por dois Centros Federais de Educação Tecnológica (CEFET-RJ e CEFET-MG) e pelas Escolas Técnicas vinculadas às Universidades Federais.

12 A Lei Federal 11.892, de 29 de dezembro de 2008 (BRASIL, 2008) criou os Institutos Federais, estabelecendo os seus objetivos. Entre eles estão fornecer educação técnica de nível médio (inclusive para o público da educação de jovens e adultos), cursos de formação inicial e continuada, superior (de tecnologias, licenciaturas, bacharelados e engenharias) e cursos de pós-graduação. Além disso, devem realizar pesquisa e extensão, levando em conta a relação com os Arranjos Produtivos Locais, com a finalidade de promover o desenvolvimento regional. 
que se refletem nelas. É importante ressaltar, que o texto da lei explicita o objetivo da emancipação do cidadão, algo que se alia a perspectiva do desenvolvimento humano, ou da expansão das capacitações.

No entanto, salientam-se os possíveis obstáculos, levantados por Frigotto, com os quais a sociedade e o governo terão que lidar: impedir que o ensino profissionalizante seja um adestramento rápido para o mercado de trabalho; e "quebrar a barreira de resistência das políticas estaduais, sob as quais está a prerrogativa da oferta do ensino médio" (FRIGOTTO, 2007, p. 1145).

Em consonância com o aumento do número de unidades voltadas para a educação profissional, as matrículas acompanham a expansão, como ilustra o Gráfico 3. De acordo com dados da SETEC, disponíveis em MEC (2014) ${ }^{13}$, o número de matrículas já teria passado de 500 mil no segundo semestre de 2012.

\section{Gráfico 3: Matrículas na Rede Federal de Educação Profissional e Tecnológica, 2003-2011}

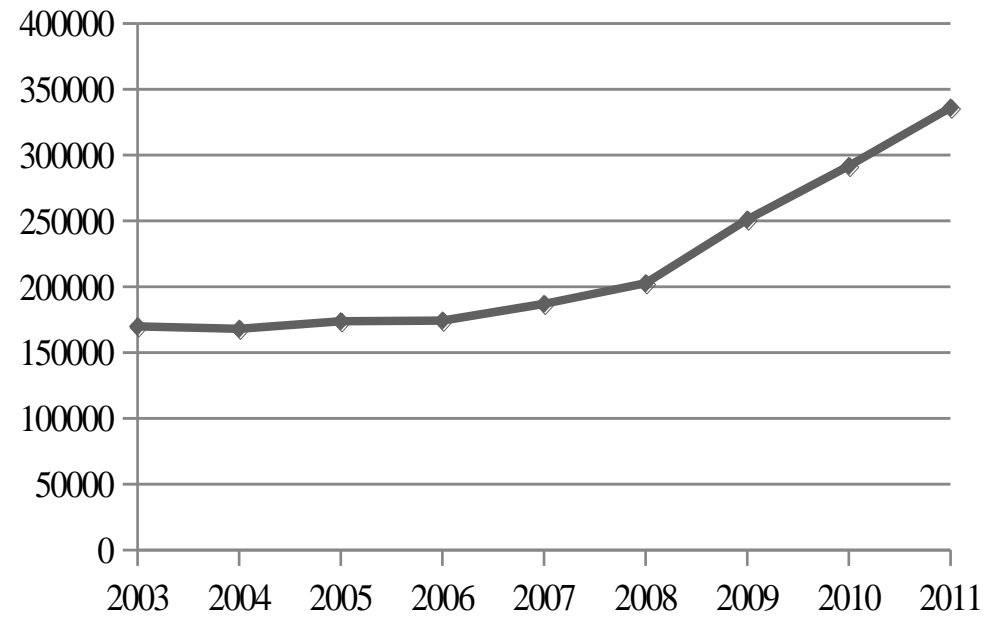

Fonte: MEC (2014). Dados: Censo INEP/CAPES.

Os investimentos na educação não se limitaram à educação profissional. Neste período foram criadas 18 novas Universidades Federais, passando assim de 45 para 63. O número de alunos também aumentou, passando, em 2003 de 583.843 matrículas, para 1.137.951 em 2013. No entanto, a estratégia adotada no governo Fernando Henrique, de expansão do ensino superior privado teve continuidade. Programas como o PROUNI ${ }^{14}$ e o FIES $^{15}$ aprofundaram o crescimento do setor privado, com o número de matrículas passando de 2.802.011 para 5.389.948 no mesmo período, como ilustra o Gráfico 4.

13 No entanto, após a deposição da presidente Dilma, este indicador deixou de ser publicado pelo MEC. 14 Programa Universidade para Todos, instituído em 2004, que concede bolsas em instituições privadas de educação superior. Frigotto (2011) destaca a aparente contradição entre o PROUNI e a expansão das universidades federais.

15 Fundo de Financiamento Estudantil, que financia estudantes em instituições privadas, com taxas de juros subsidiadas. 
Gráfico 4: Matrículas no Ensino Superior, 2003-2013

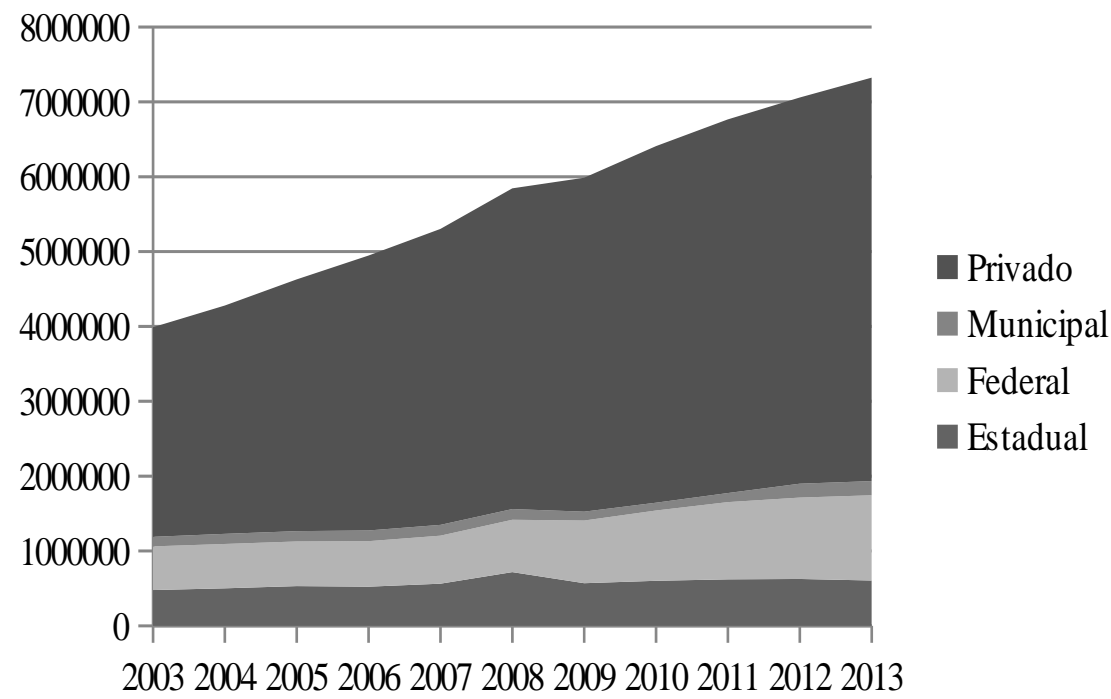

Fonte: MEC (2014).

Para dar suporte à expansão das universidades e dos Institutos Federais, com formação de docentes e pesquisadores, também ocorreu expansão da pós-graduação. Entre 2004 e 2012 o número de concluintes de cursos de doutorado aumentou de 41.313 para 79.478, de mestrado de 69.401 para 109.515 , e de mestrado profissional de 5.814 para 14.724. A evolução da pós-graduação foi constante no período em questão nas três modalidades e liderada pelas instituições federais. Parte desta expansão pode ser atribuída ao aumento do número de bolsas de pós-graduação concedidas. Em 2002 foram concedidas 13.013 bolsas (7.962 de mestrado e 5.051 de doutorado), enquanto que em 2012 foram 77.757 (2.914 de mestrado profissional, 43.591 de mestrado, 27.589 de doutorado e 3.663 de pós-doutorado). Aliado a isso, houve a ampliação dos recursos para assistência estudantil, e a criação do Programa Ciência Sem Fronteiras, que enviou estudantes brasileiros para intercâmbios em universidades no exterior.

Dado este cenário, o gasto com educação ${ }^{16}$ atingiu seu maior nível na história (HERRLEIN JÚNIOR, 2011, p.17), como pode ser observado nos Gráficos 1 e 5.

16 Embora a perspectiva da abordagem das capacitações expanda o foco da análise para além da renda, esta não deve ser menosprezada. Por conta disso, a despesa com educação é uma variável relevante, especialmente considerando-se a defasagem histórica brasileira na educação. A elevação do investimento público em educação colocou o percentual em relação ao PIB acima da média dos países membros da OECD, não obstante, como se trata de uma comparação com países desenvolvidos, a despesa per capita é significativamente menor. 


\section{Gráfico 5: Investimento público total em educação em relação ao PIB (\%), 2000 -} 2013

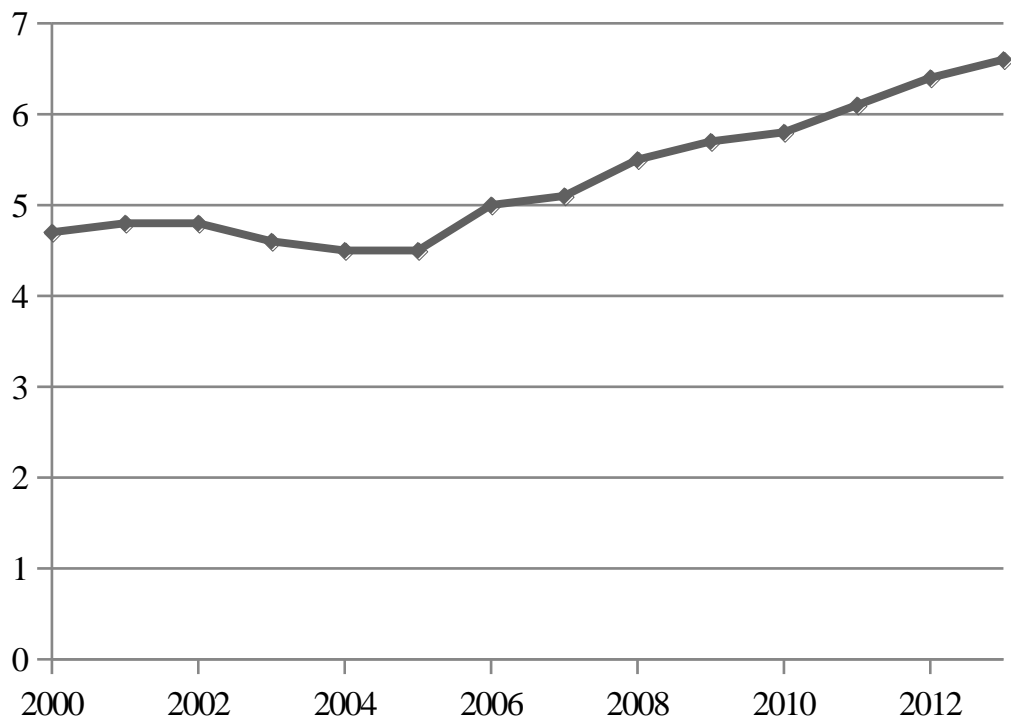

Fonte: MEC (2014).

Com a retomada dos investimentos, os principais desafios da educação no Brasil, deveriam ser, portanto, o aumento da qualidade do ensino ${ }^{17}$ e a continuidade da expansão do ensino médio, superior e profissional, visto que o ensino fundamental já atingiu níveis próximos da universalidade. No entanto, a recente mudança conjuntural faz com que a prioridade se torne a manutenção do que se expandiu no período em análise.

Quanto a qualidade do ensino, apesar do baixo desempenho em testes internacionais padronizados ${ }^{18}$, o Brasil tem mostrado significativa melhora. Entre 2003 e 2012 a pontuação dos estudantes brasileiros na prova de matemática do PISA ${ }^{19}$ aumentou a uma média anual de 4,1 pontos, chegando a 391 pontos. Ainda assim, muito abaixo de 494, a média dos países desenvolvidos (OECD, 2013). O desempenho em leitura também mostrou evolução (1,2 pontos ao ano, chegando a 410 pontos em 2012), assim como em ciências (2,3 pontos ao ano, atingindo 405 no mesmo período). É notável que tenha ocorrido expansão do ensino com melhora do desempenho dos estudantes. Além disso, os dados desagrados mostram uma enorme disparidade interna, tanto entre estados quanto entre redes de ensino. Como ilustra Corbucci (2011), a nota média dos alunos a Rede

17 "o desafio é de universalizar o ensino médio com esta qualidade teórica, técnica e política" (FRIGOTTO, 2007, p. 1146).

18 Embora estes testes possam ser objeto de crítica, ela foge ao escopo deste artigo. A menção aos resultados se faz necessária, pois muitas vezes a avaliação da qualidade da educação e a comparação internacional, especialmente pela imprensa, destaca os resultados nestes exames.

19 Programme for International Student Assessment, um exame aplicado em estudantes de 15 anos pela OECD (The Organisation for Economic Co-operation and Development) nos seus 34 países membros e em outros 31 países (OECD, 2013). Como a maioria dos países que se submetem ao exame são mais desenvolvidos que o Brasil, o fato do Brasil ocupar as últimas posições no ranking não é algo anormal. 
Pública Federal é superior a da maioria dos países membros da OECD e semelhante a dos alunos japoneses.

Não obstante, o desempenho brasileiro ainda é insatisfatório nos indicadores quantitativos referentes à população adulta. A média de anos de estudo da população brasileira com mais de 25 anos (7,2 anos de estudo), é igual a do Zimbábue, país com a pior colocação no ranking de Desenvolvimento Humano (PNUD, 2010). Isto demonstra que ainda há um grande estoque de pessoas necessitando de atendimento por programas voltados à formação inicial e continuada e formação de nível médio, para jovens e adultos, em programas ofertados pelos Institutos Federais. É importante fazer a ressalva que o próprio PNUD reconhece que este indicador é mais influenciado pelo desempenho passado, ou seja, o esforço recente de inclusão de jovens, não é refletido em tal tipo de indicador:

A alfabetização e os anos de escolaridade reflectem o acesso à educação (ou a sua inexistência) no passado relativamente a pessoas que são adultas hoje; por conseguinte, o progresso medido pode não reflectir os recentes avanços na escolaridade para a população jovem. (PNUD, 2010, p. 39).

A despeito do mau desempenho em termos internacionais, recentemente houve avanços nos anos de escolaridade da população adulta, passando de 5,2 em 1992 para 7,5 em 2009 (IPEA, 2010). Mantido o ritmo de crescimento, levaria, ainda, mais cinco anos, para que na média a escolaridade brasileira atingisse o ensino fundamental, exigido pela constituição. Há de se salientar ainda as desigualdades regionais, com a região sudeste em melhor situação $(8,2)$, acompanhada de perto pela região sul, e com a região nordeste apresentando pior desempenho (6,3). O avanço recente se reflete na escolaridade da população jovem. Na população entre 18 e 24 anos, a média de anos de estudo é de 9,6 anos (IBGE, 2012).

Ainda quanto aos dados divulgados pelo PNUD (2010, p. 202), cabe destacar o índice de alfabetização de adultos (com idade superior a 15 anos) de 90,0\%, implica numa parcela de $10 \%$ da população analfabeta. Outro dado relevante é o da população com pelo menos educação secundária (com idade superior a 25 anos): 21,9\%. Os dados mostram que quanto maior a idade de determinado grupo populacional, maior o hiato educacional. Isto é, a situação da população brasileira, demanda a existência de programas voltados para jovens e adultos.

Outra questão importante é a diferença entre a escolaridade da população urbana metropolitana (8,7 anos de estudo) e da população rural (4,8 anos de estudo). Neste sentido, a iniciativa de interiorização do ensino, de levar tanto os Institutos Federais quanto Universidades para o interior do país, faz sentido. A atração de estudantes para estudar em unidades no interior reduz parte da pressão de migração para as capitais em busca de estudo, favorecendo uma estratégia de desenvolvimento regional. Entre 2000 e 2010, cresceu a participação das cidades do interior na oferta de vagas das instituições públicas, mesmo assim, no interior das regiões Norte, Nordeste e Centro-Oeste ainda há uma expressiva demanda represada (CORBUCCI, 2014). Além da dimensão espacial, 
Corbucci (2014) também traz dados referentes a cor/etnia e faixa de renda. Em todas as faixas de renda, a taxa de frequência na educação superior é maior entre os brancos, do que entre pardos e negros. De maneira já esperada, a frequência é maior entre as faixas de renda mais elevadas.

Os avanços teóricos da economia, no sentido de incorporar a dimensão humana no desenvolvimento, foram fundamentais e balizadores para as políticas adotadas.

\section{PERSPECTIVA DO DESENVOLVIMENTO HUMANO: A ABORDAGEM DAS CAPACITAÇÕES}

A abordagem das capacitações, formulada a partir das contribuições teóricas de Amartya Sen, possui um importante papel ao colocar a dimensão humana em uma posição central no desenvolvimento. Ela se afasta de maneira significativa do pensamento econômico dominante, focado exclusivamente no crescimento econômico, e que quando atento quanto à saúde e à educação, o faz em termos de capital humano.

Amartya Sen retoma muitas preocupações recorrentes nos economistas clássicos, sobretudo Adam Smith, assim como da filosofia aristotélica, que estavam completamente ausentes do pensamento neoclássico. Os problemas econômicos envolvem claramente uma dimensão logística, relacionada com problemas de engenharia, mas por outro lado, o progresso deve ser julgado em termos do que traz para as vidas dos seres humanos (SEN, 1988), o que suscita importantes questionamentos filosóficos. Ele clama, portanto, por um resgate da ética na economia (SEN, 1999). Nesta perspectiva o ser humano está numa posição central, as pessoas são consideradas a verdadeira riqueza das nações.

Esta abordagem é crítica à visão utilitarista, afirmando que "a utilidade não representa adequadamente o bem-estar" (SEN, 1999, p. 63). A condição de agente deve ser considerada, sendo esta muito mais ampla do que supõe a lógica utilitarista. Desta forma, o desenvolvimento deve ser visto em termos da expansão das capacitações das pessoas em direção ao tipo de vida que elas valorizam e possuem razões para valorizar.

As capacitações são a resposta para a pergunta do que uma pessoa é apta a fazer e a ser. Elas são as liberdades substantivas, um conjunto de oportunidades para escolher e agir (NUSSBAUM, 2011, p. 20). A Abordagem das Capacitações vê o desenvolvimento como "um processo de expansão das liberdades reais que as pessoas desfrutam" (SEN, 2000, p. 52). A expansão da liberdade é considerada como o fim primordial e o principal meio do desenvolvimento (SEN, 2000, p. 52).

Sen expande a análise do desenvolvimento econômico para além da esfera da renda. O aumento da renda não deve ser vista como um fim em si mesmo, mas como um meio para melhora do bem estar humano. O desenvolvimento deve ser avaliado em termos de expansão das capacitações (EVANS, 2008, p. 4-5). A expansão das capacitações depende também do acesso à saúde (redução da mortalidade e morbidade, por exemplo), educação, igualdade de gênero, liberdade política, direitos civis básicos e 
ausência de opressão. O objetivo de Sen não é fazer uma sistematização dos valores envolvidos nas capacitações, seu posicionamento se dá por meio de exemplos, comparações e implicações (NUSSBAUM, 2011). Por causa disso, ele nunca fez uma lista de capacitações centrais, como fez Martha Nussbaum $(2000)^{20}$.

As contribuições feitas por Sen, somadas às de Haq (1995), tiveram importante aplicação prática, uma vez que esta base teórica serviu de apoio para a elaboração e o cálculo, pelas Nações Unidas, do Índice de Desenvolvimento Humano (IDH), que inclui a educação. Da mesma maneira, influenciou as políticas implantadas por esta e por outras organizações multilaterais, como o Banco Mundial ${ }^{21}$. A partir daí, mais atenção passou a ser dada à qualidade de vida e às liberdades individuais.

A obra de Sen serviu de inspiração para reformulação no trabalho das Nações Unidas, bem que deslocaram parte do foco do crescimento econômico, estritamente atento ao PIB dos países, para o desenvolvimento econômico em sentido amplo, atento as condições de vida da população. O PNUD (2010, p. 39) reconhece, portanto, as contribuiçõos da abordagem das capacitações, destacando que a educação expande outras liberdades, resistindo à exploração, levando a vidas melhores e mais saudáveis.

A importância da democracia foi destacada por Sen, que afirmou que os grandes episódios de morte por fome na humanidade, ocorreram em regimes não democráticos. Um tema central em sua obra é a escolha social, que não só é possível, como é necessária. O debate político e a discussão são fundamentais para a definição dos objetivos do desenvolvimento. Se o desenvolvimento deve promover o que as pessoas valorizam, a escolha social deve partir de um processo democrático. A educação, portanto, deve preparar as pessoas para o exercício da cidadania, ao invés de preparar "capital humano" para o mercado (NUSSBAUM, 2010).

Neste aspecto, vale ressaltar que no Brasil, os gastos com educação aumentaram nos períodos democráticos e diminuíram durante o período da ditadura militar, como já ilustrado. Quando a população teve a possibilidade de participar da escolha social, como ocorreu no Brasil democrático, a demanda por mais educação se fez presente.

Embora a democracia seja fundamental na perspectiva do desenvolvimento como liberdade, Martha Nussbaum faz um importante alerta: democracias em todo mundo estão menosprezando, e consequentemente negligenciando, habilidades que são necessárias para manter as democracias vitais, respeitosas e responsáveis (NUSSBAUM, 2010, p. 77). Isto se deve por uma visão utilitarista da educação, que privilegia aquilo que pode gerar lucros em curto prazo. Enquanto isso, uma pedagogia socrática, que forme alunos

20 A lista das capacitações funcionais centrais inclui: vida; saúde corporal; integridade física; sentido, imaginação e pensamento (neste aspecto que está incluída a educação); emoções; razão pratica; afiliação; outras espécies; diversão; controle sobre o ambiente (tanto político quanto material) (NUSSBAUM, 2000, p. 77-81). Esta autora ainda cita a vantagem das "capacitações" em relação aos "direitos", por não dependerem de uma cultura particular, ou de uma tradição histórica específica (NUSSBAUM, 2000, p. 99). 21 A visão anterior do Banco Mundial, antes desta inflexão, foi alvo de críticas por Sen, que alertou: "o poder de fazer o bem, quase sempre anda junto com a possibilidade de fazer o oposto" (SEN, 2000, p. 11). 
críticos, reflexivos e com capacidade de argumentação, é negada, em detrimento a preparação para testes padronizados.

Nussbaum (2010) chama atenção para o fato de artes e humanidades estarem sendo, de maneira generalizada ao redor mundo, descartadas nos ensinos fundamental, médio e superior. $O$ resultado é possivelmente comprometedor para o futuro da democracia, pois desestimula o pensamento crítico, a cidadania e a capacidade de compreensão de outras pessoas. No lugar disso, são privilegiadas tecnologias aplicadas, visando retorno de curto prazo.

A dimensão internacional de muitos problemas traz dificuldades éticas, e operacionais, suscitando a necessidade de readequação de muitos arranjos institucionais globais. Mesmo para defender a globalização, Sen reconhece que é necessário escutar o que se opõem a ela, pois as questões éticas e humanas que estes levantam devem ser consideradas:

O capitalismo global está muito mais preocupado em expandir o domínio das relações de mercado do que, por exemplo, em estabelecer a democracia, expandir a educação elementar, ou incrementar as oportunidades sociais para os pobres do mundo. (SEN, 2010, p. 28).

Este argumento se assemelha ao de Nussbaum (2010), que alertou para a importância da educação voltada para a democracia. Sen (2010, p. 29) ressalta ainda que muitas vezes os negócios internacionais preferem autocracias a democracias participativas.

Sen também critica a abordagem tradicional de "capital humano", pois esta reduz as qualidades humanas apenas para o sentido de ampliar o capital na produção. Uma pessoa se torna mais eficiente na produção de mercadorias, por meio da educação. Este reconhecimento é visto como uma iniciativa enriquecedora, mas Sen destaca que é preciso ir além. Os benefícios da educação não se limitam a isso. Mesmo que não se reflitam na renda, a pessoa irá fazer uma série de coisas melhor: ler, comunicar, argumentar, ter melhores condições de escolha e ser tratada com mais consideração pelos demais (SEN, 2000, p. 332-334). A perspectiva da abordagem das capacitações vê a educação além do seu papel como capital humano. A capacidade humana deve levar em consideração estes outros papéis. A educação não serve apenas para tornar o trabalhador mais produtivo, como parece ser o objetivo dos economistas neoclássicos. A finalidade da educação é tornar o ser humano livre e autônomo. A pobreza não é vista apenas como insuficiência de renda, mas também como limitação aos sistemas de saúde, ensino, privações de liberdade, etc.

O aumento da renda é importante, especialmente em países com nível de renda baixo, e não deve ser menosprezado. Pois, ao expandir os intitulamentos econômicos da população, ela constitui uma liberdade instrumental fundamental, permitindo que as pessoas tenham acesso a mercadorias. É importante ressaltar que a maneira com que esta renda é distribuída, também afetará diretamente as capacitações. 
Políticas de transferência de renda, como as aplicadas no Brasil, ampliam as capacitações de seus cidadãos. Apenas isso não é suficiente, mas a redução das taxas de desemprego e a elevação salarial real são medidas que expandem os intitulamentos e as liberdades dos cidadãos, e estão de acordo com a proposição feita por Sen. Por outro lado, a melhora nas condições de educação pode ter um impacto limitado, se os indivíduos não encontrarem emprego.

No entanto, apesar dos avanços em não ver o desenvolvimento apenas na dimensão do crescimento econômico, a visão focada no crescimento continua bastante influente, principalmente na formulação de políticas públicas (NUSSBAUM, 2010, p. 1415). A reação ao cenário de crise econômica na Europa tem levado a medidas que não consideram as contribuições da abordagem das capacitações.

\section{CONSIDERAÇÕES FINAIS}

Se o modelo anterior baseado no ensino privado limitava as possibilidades da parcela mais pobre da população, podemos dizer que o fornecimento de educação gratuita ou subsidiada (seja via PROUNI e FIES, seja através da expansão das instituições federais) amplia as possibilidades da totalidade da população, incluindo uma parcela importante da população que se encontrava excluída, expandindo suas capacitações.

A democracia favorece os investimentos em educação, que, por sua vez, fortalecem a própria democracia. Os dados relativos aos investimentos públicos no Brasil ilustram esta questão: o gasto tende a aumentar nos períodos democráticos. Este fato fortalece os argumentos de Sen e Nussbaum, entre outros autores, que valorizam a importância da democracia.

A política educacional de expansão da educação profissional, técnica e tecnológica, aliada as de expansão do ensino universitário e da pós-graduação, aumenta as liberdades individuais e as capacitações dos cidadãos. Cabe ressaltar, que dado o estoque expressivo de pessoas excluídas da educação no passado, ainda há necessidade de avançar mais, a fim de incluí-las, visando o desenvolvimento do país. Mesmo assim, já é visível a melhora em diversos indicadores, como acesso à educação superior, ou pela média de anos de escolaridade da população.

O avanço significativo da situação educacional no Brasil, somada às medidas de distribuição de renda, redução do desemprego e elevação de renda, mostram-se compatíveis com as formulações teóricas da Abordagem das Capacitações. Com isso, as transformações recentes da economia brasileira, vão no sentido de expansão das capacitações, configurando um período de desenvolvimento, e não apenas crescimento.

Considerando a visão de Amartya Sen, a educação para o trabalho pode levar os trabalhadores a uma posição de autonomia, adquirindo liberdade e participando dos processos democráticos, com isso, promovendo o verdadeiro desenvolvimento econômico. 
Por fim, cabe fazer a ressalva das possíveis limitações desta expansão. O foco excessivamente tecnológico pode constituir um problema, como constam nos alertas feitos por Martha Nussbaum, de entrar em contradição com o ensino de valores democráticos, e por Gaudêncio Frigotto, de que este se torne apenas um adestramento para o mercado de trabalho. Para isto, são necessários estudos que avaliem qualitativamente a expansão, bem como o desenvolvimento de políticas públicas de monitoramento em consonância com os princípios do ensino democrático e da deliberação coletiva.

\section{REFERÊNCIAS}

BARBOSA FILHO, Fernando de Holanda; PESSÔA, Samuel. Educação e Desenvolvimento no Brasil. in: VELOSO, Fernando; FERREIRA, Pedro Cavalcanti; GIAMBIAGI, Fabio; PESSÔA, Samuel (org.). Desenvolvimento Econômico: uma perspectiva brasileira. Rio de Janeiro: Elsevier, 2013.

BRASIL. Lei 11.892, 29 de dezembro de 2008.

CAMPOS, Marcelo Mallet Siqueira. Estado desenvolvimentista e a ampliação das capacitações: uma possível convergência. Cadernos do Desenvolvimento, Rio de Janeiro, v.9, n. 14, p. 119-135, jan.-jun. 2014.

CARVAlHO, José Murilo de. A construção da Ordem. Teatro de sombras. $3^{\mathrm{a}}$. ed. Rio de Janeiro: Civilização Brasileira, 2007.

CEPAL. Pactos para la igualdad: Hacia un futuro sostenible. Santiago: CEPAL, 2014.

CHANG, Ha-Joon. Hamlet without the Prince of Denmark: How development has disappeared from today's 'development' discourse. in: KHAN; CHRISTIANSEN (ed.) Towards New Developmentalism: Markets as Means Rather than Masters. Routledge: Abington: 2010.

CORBUCCI, Paulo Roberto. Dimensões estratégicas e limites do papel da educação para o desenvolvimento brasileiro. Revista Brasileira de Educação, v. 16, n. 48, set-dez. 2011.

CORBUCCI, Paulo Roberto. Evolução do acesso de jovens à educação superior no Brasil. Texto para discussão. Instituto Nacional de Pesquisa Econômica Aplicada. Brasília: IPEA, 2014.

EVANS, Peter. O Estado como problema e como solução. Lua Nova, n.28-29, Abr., 1993.

EVANS, Peter. Collective Capabilities, Culture, and Amartya's Sen Development as Freedom. Studies in Comparative International Development, v. 37, n. 2, p. 54-60, Summer 2002.

EVANS, Peter. Além da "Monocultura Institucional": Instituições, capacidades e o desenvolvimento deliberativo. Sociologias, Porto Alegre, v. 5, n. 9, p. 20-63, jan.-jun., 2003. 
EVANS, Peter. The Challenges of the Institutional Turn: New Interdisciplinary Opportunities in Development Theory. in: NEE, Victor; SWEDBERG, Richard. The Economic Sociology of Capitalism. Princeton: Princeton University Press, 2005.

FERREIRA, Sergio Guimarães; VELOSO, Fernando. A Escassez de Educação. in: GIAMBIAGI, Fabio (et. al.). Economia Brasileira Contemporânea. Rio de Janeiro: Elsevier, 2005.

FONSECA, Pedro C. D. Sobre a Intencionalidade da Política Industrializante do Brasil na Década de 1930. Revista de Economia Política, v. 23, n. 1, jan-mar, 2003.

FRIGOTTO, Gaudêncio. A relação da educação profissional e tecnológica com a universalização da educação básica. Educ. Soc. Campinas, vol. 28, n.100, p.1129-1152, Out. 2007.

FRIGOTTO, Gaudêncio. Os circuitos da história e o balanço da educação no Brasil na primeira década do século XXI. Revista Brasileira de Educação, v. 16, n. 46, jan.abr., 2011.

HAQ, Mahbub ul. Reflections on human development. New York: Oxford University Press, 1995.

HERRLEIN JÚNIOR, Ronaldo. Estado democrático e desenvolvimento no Brasil contemporâneo: um ensaio de economia política. Texto para discussão. Universidade Federal do Rio Grande do Sul. Porto Alegre: UFRGS, 2011.

HERRLEIN JÚNIOR, Ronaldo. A Construção de um Estado Democrático para o Desenvolvimento no Século XXI. Texto para discussão. Instituto de Pesquisa Econômica Aplicada. Brasília: IPEA, 2014.

HOBSBAWM, Eric. A Era das Revoluções: Europa 1789-1848. 28. ed. São Paulo: Paz e Terra, 2006.

IBGE. Indicadores de Desenvolvimento Sustentável: Brasil 2010. Rio de Janeiro: IBGE, 2011.

IBGE. Síntese de Indicadores Sociais: Uma Análise das Condições de Vida da População Brasileira - 2012. Rio de Janeiro: IBGE, 2012.

IPEA. PNAD 2009 - Primeiras análises: Situação da educação brasileira: avanços e problemas. Brasília: IPEA, Comunicados do IPEA, n 66, 2010.

KLIKSBERG, Bernardo. Repensando o Estado para o Desenvolvimento Social: Superando Dogmas e Convencionalismos. São Paulo: Cortez Editora, 1998.

KUNZE, Nádia Cuiabano. O surgimento da rede federal de educação profissional nos primórdios do regime republicano brasileiro. Revista brasileira de educação profissional e tecnológica. Brasília: MEC, SETEC, 2009.

LANDES, David. The Wealth and Poverty of Nations: Why some are rich so rich and some so poor. New York: W.W. Norton, 1999.

MEC. Painel de Controle do MEC. Disponível em: http://painel.mec.gov.br/ Acesso em 23/05/2014. 
NUSSBAUM, Martha. Women and Human Development: The Capabilities Approach. Cambridge: Cambridge University Press, 2000.

NUSSBAUM, Martha. Not for profit: why democracy needs humanities. Princeton: Princeton University Press, 2010.

NUSSBAUM, Martha. Creating Capabilities: The Human Development Approach. Cambridge: The Belknap Press of Harvard University Press, 2011.

OECD. Pisa 2012 Results in Focus: What 15-years-old know and what they can do with what they know. Vol. I. Paris: OECD, 2013.

PNUD. Relatório de Desenvolvimento Humano 2010: A verdadeira riqueza das nações: Vias para o desenvolvimento humano. New York: Programa das Nações Unidas para o Desenvolvimento, 2010.

PNUD. Relatório de Desenvolvimento Humano 2013: A Ascensão do Sul: Progresso Humano num Mundo Diversificado. New York: Programa das Nações Unidas para o Desenvolvimento, 2013.

SEN, Amartya. The concept of Development. in. CHENERY, Hollis; SRINIVASAN, T. Handbook of Development Economics. Amsterdam: North Holland, 1988.

SEN, Amartya. Sobre ética e economia. São Paulo: Companhia das Letras, 1999.

SEN, Amartya. Desenvolvimento como Liberdade. São Paulo: Companhia das Letras, 2000.

SEN, Amartya. Desigualdade reexaminada. 2. ed. Rio de Janeiro: Record, 2008.

SEN, Amartya. Como julgar a globalização. in: SEN, Amartya; KLIKSBERG, Bernardo. As pessoas em primeiro lugar: A ética do desenvolvimento e os problemas do mundo globalizado. São Paulo: Companhia das Letras, 2010.

WINCKLER, Carlos Roberto; SANTAGADA, Salvatore. A educação profissional técnica de nível médio no Brasil: transição para um novo modelo? Indic. Econ. FEE, Porto Alegre, v. 39, n.3, p. 97-110, 2012. 